Research Paper:

\title{
The Role of Attachment Styles and Spiritual Intelligence in Predicting Women's Emotional Divorce
}

\author{
Zahra Shirzadi $^{1}$ (D), Reza Khakpour ${ }^{1 *}$ (D), Anahita Khodabakhshi-Koolaee ${ }^{2}$ (D) \\ 1. Department of Counseling \& Guidance, Faculty of Human Science, Rudehen Branch, Islamic Azad University, Rudehen, Iran \\ 2. Department of Psychology and Education Sciences, Faculty of Humanities, Khatam University, Tehran, Iran.
}

\begin{tabular}{|l|l|l}
\hline $\begin{array}{c}\text { Use your devic to scan } \\
\text { and read the article online }\end{array}$ & $\begin{array}{l}\text { Citation: Shirzadi, Z., Khakpour, R., \& Khodabakhshi-Koolaee, A., 2021. The Role of Attachment Styles and Spiritual } \\
\text { Intelligence in Predicting Women's Emotional Divorce. Journal of Client-Centered Nursing Care, 7(1), pp. 17-26. https://doi. } \\
\text { org/10.32598/JCCNC.7.1.350.1 }\end{array}$ \\
dointtps://doi.org/10.32598/JCCNC.7.1.350.1
\end{tabular}

\section{(i) (9)}

Article info:

Received: 10 Jul 2020

Accepted: 23 Nov 2020

Published: 01 Feb 2021
Keywords:

Divorce, Object attachment, Spirituality, Intelligence, Women

\begin{abstract}
A B S T RA C T
Background: Emotional divorce refers to a situation in which the emotional relationship, support, passion, warmth, attention, love, and intimacy between couples (husband \& wife) decline or diminish. Such conditions lead to an unaffectionate marital life to the point that the couples are only together under one roof. Accordingly, the present study aimed to explore the role of attachment styles and spiritual intelligence in predicting emotional divorce in women.
\end{abstract}

Methods: This study employed a descriptive-correlational design. The research population included all women filing for divorce who were referred to marriage counseling and couple therapy centers in districts 5 and 6 in Tehran City, Iran, in 2020. In total, 400 women who met the inclusion criteria were selected as the study participants using voluntary response and convenience sampling techniques. The required data were collected by the Emotional Divorce Scale, the Adult Attachment Scale, and the Self-Report Measure of Spiritual Intelligence. The collected data were analyzed using the multiple regression analysis method in SPSS V. 22.

Results: The obtained results suggested a significant positive relationship between the anxiousavoidant attachment style and emotional divorce $(\mathrm{P}<0.01)$. Furthermore, there was a significant negative relationship between spiritual intelligence and emotional divorce; the higher the spiritual intelligence, the lower the emotional divorce $(\mathrm{P}=0.02)$. Accordingly, spiritual intelligence and anxious-avoidant attachment style can predict emotional divorce (Multiple Regressions $=-0.58$ ).

Conclusion: The present study data suggested that premarital education and counseling before spouse selection help in examining the personality traits of the parties. Moreover, paying attention to the role of health professionals, such as family counselors, psychologists, and psychiatric nurses in providing premarital counseling and education to couples and emphasizing the role of spiritual intelligence and attachment styles may prevent emotional separation and divorce among couples.

"Corresponding Author:

Reza Khakpour, PhD.

Address: Department of Counseling \& Guidance, Faculty of Human Science, Rudehen Branch, Islamic Azad University, Rudehen, Iran

Tel: +98 (912) 0046578

E-mail: rkhakpour@riau.ac.ir 


\section{Highlights}

- Emotional divorce in couples presents detrimental effects on their relationship and the whole family, including children.

- Several psychological and personality factors are involved in couples' communication problems. This research has paid special attention to attachment styles and spiritual intelligence.

- The present study results indicated that anxious and avoidant insecure attachment styles predict emotional divorce in women. Furthermore, women with less spiritual intelligence achieved higher scores in the emotional divorce questionnaire and vice versa.

\section{Plain Language Summary}

Emotional divorce means emotional, romantic, communicative, and sometimes even sexual separation between the couples. They live under one roof but are not together. Research suggested that emotional divorce in couples has irreversible effects on the psychological adjustment of their children in the future. This study was conducted to investigate the role of attachment styles and spiritual intelligence in predicting emotional divorce in women. The study results revealed that insecure attachment and low spiritual intelligence can predict emotional divorce in women.

\section{Introduction}

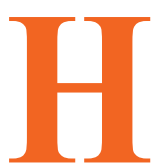

aving a satisfying or romantic marriage is the goal of almost all couples. Therefore, it is not surprising that the dissolution of the marital relationship can present negative consequences for numerous couples (Solomon \& Jackson 2014). Emotional divorce is a type of separation whereby couples live together under one roof without any love and affection between them and are bound together through a legal contract (Gottman \& Gottman 2008). In emotional divorce, the structure of the family is preserved; however, the family is void inside, because positive interactions between couples disappear and are replaced by negative patterns (Olson \& DeFrain 2002). Emotional divorce is caused by a lack of positive interactions with the partner, the non-satisfaction of emotional needs, sexual dissatisfaction, physical unattractiveness, infidelity, financial problems, chronic illnesses, and physical abuse; such conditions lead to the generation of symptoms of anxiety, depression, guilt, frustration, withdrawal from social activities, and pessimistic and persistent attitudes about self, partner, and the future (Pines 2013).

Some psychological and personality traits of couples are involved in the occurrence of emotional divorce. For example, individuals with insecure or ambivalent attachment styles are less likely to remain stable in their marital relations (Ozmena \& Atik 2010). Women with an anxious attachment style tend to develop conflicts with their husbands; however, they lack problem-solving skills to prevent the continuation of conflicts and quarrels. Previous studies signified the avoidant attachment style and problem-solving skills in women as critical predictors of the odds of divorce in them (Fakhri, Mahdavianfard \& Kimiaee 2018). Furthermore, attachment styles can predict special love and marital relationships. For example, prior research reported a significant negative relationship between the avoidant attachment style and love (McDonald, Patch \& Figueredo 2016). Besides, ambivalent and anxious attachment styles have higher predictive power than other attachment styles (Yárnoz-Yaben 2010).

Another issue that seems to be effective in emotional divorce is spiritual intelligence. Spiritual intelligence represents a set of spiritual abilities, capacities, and resources; the application of such skills in daily life increases a person's adaptability. By definition, spiritual intelligence plays a vital role in solving existential problems and finding meaning and purpose in the actions and events of daily life (King 2008).

Spiritual intelligence causes individuals to consider problems more patiently, try harder to find solutions, and better endure the hardships of life (King, Mara \& DeCicco 2012). Some studies suggested that individuals with a lower level of spiritual intelligence encounter further familial and personal issues (Bhullar 2015). Spiritual intelligence and wisdom are characterized by features, such as cognition and emotions, as well as humility, empathy, and compassion (Khodabakshi-Koolaee et al. 2019A). Individuals with a sense of meaning and pur- 
pose in life more effectively cope with problems in times of crisis. Besides, faith in God assists them to experience less psychological distress (Liu \& Froese 2020).

Previous studies demonstrated a positive and significant relationship between secure attachment style and spiritual intelligence. Individuals with higher levels of spiritual intelligence experience greater mental health and happiness (Amirian \& Fazilat-Pour 2016). Furthermore, individuals with higher levels of spiritual intelligence also experience more secure attachment styles. Moreover, higher levels of spiritual intelligence predicted higher levels of connectedness and secure attachment (Carnesecca 2020).

Emotional divorce is not only a problem for the couples in the family, but also is worse than a formal divorce. This is because of its hidden dimensions and the negative effects on family-related relationships. For example, parental emotional divorce affects the levels of depression, anxiety, stress, and aggression in their children. Hashemi and Homayuni (2017) found that the children of emotionally divorced parents reported higher levels of emotional and behavioral problems, compared to their counterparts of legally divorced parents. They also reported higher levels of depression, anxiety, stress, and aggression. The authors concluded that emotional divorce is more harmful than legal divorce. Problematic parental relationships also adversely affect their children's relationships later in adulthood (Roper, Fife \& Seedall 2020; Fraley \& Hefferman 2013). The psychological and personal characteristics of individuals are of considerable importance in their marriage. Thus, this study aimed to determine the role of attachment styles and spiritual intelligence in predicting emotional divorce in women.

\section{Materials and Methods}

This was an applied descriptive-correlational study. The research population included all women applying for divorce who were referred to marriage counseling and couple therapy centers in districts 5 and 6 in Tehran City, Iran, in 2020. The participants were selected based on the inclusion and exclusion criteria of the research. The inclusion criteria were as follows: obtaining the cutoff score of emotional divorce; having at least a diploma degree to understand the meaning of the items in the questionnaires, and an age range of 20-40 years. The exclusion criteria were remarriage and not completing the questionnaires (partially/fully). A large number of individuals living in districts 5 and 6 of Tehran met the inclusion criteria of the study; thus, the research participants were selected using voluntary response and conve- nience sampling technique. Following Klein's proposal, the 10:1 rule was used. Besides, given the possibility of the participants' dropout, 400 women were selected as the study participants.

The instruments used to collect the data are described as follows:

The Emotional Divorce Scale (EDS): The scale was developed by Katz and Gottman (1997). This scale contains 24 items. Each item is scored on a two-point scale; Yes (1) or No (0). The scale contains statements about different aspects of married life that one may agree or disagree with. The minimum and maximum scores obtained by a respondent are 0 and 24, respectively. A score of 8 and higher indicates that the individual's married life is subject to separation and there exist signs of emotional divorce (Gottman 2002). Khodabakhshi-Koolaee et al. reported the reliability of this scale equal to 0.91 using Cronbach's alpha coefficient. The formal validity of the scale was confirmed by experts (KhodabakhshiKoolaee et al. 2019B). In this study, the reliability index of the scale was calculated as 0.78 using Cronbach's alpha coefficient.

The Adult Attachment Scale (AAS): This scale provides a self-assessment of relationship-building skills and a self-report of forming attachment relationships to close attachment figures (Collins \& Read 1990). The scale contains 18 items scored on a 5-point Likert-type scale $(1=$ not at all characteristic of me, $5=$ very characteristic of me). Factor analysis data suggested the scale contains 3 subscales each with 6 items detailed, as follows:

- Dependence (D): It measures the extent to which a person feels he/she can depend on others to be available when needed.

- Closeness (C): It measures the extent to which a person is comfortable with closeness and intimacy.

- Anxiety (A): It measures the extent to which a person is worried about being abandoned or unloved Collins and Read (1990).

Anxiety subscale (A) corresponds to the anxiety-ambivalent attachment style. Moreover, the closeness subscale (C) is a bipolar dimension that contrasts secure and avoidant descriptions. Therefore, closeness (C) corresponds to secure attachment, and the dependency scale (D) is almost opposite to avoidant attachment. Collins's and Revised Adult Attachment Scale (RAAS)is administered in 10 minutes either individually or in groups. Each item is 
scored 0 to 4 for options 1 to 5 . Items $1,6^{*}, 8^{*}, 12,13$, and $17^{*}$ measure secure attachment, and items $5^{*}, 2,16^{*}$, 14,7 , and $18^{*}$ assess avoidant attachment style. Finally, items 3, 4, 9, 10, 11, and 15 measure ambivalent-anxiety attachment style. Options 1 to 5 are the items to be scored reversely (the items marked with*) are scored as 4, 3, 2, 1 , and 0 , respectively. The items marked with an asterisk should be scored in reverse before calculating their total score. The total score of each subscale is measured as the sum of the scores of the 6 items.

Collins and Read (1990) reported the Cronbach's alpha coefficient values for secure, avoidant, and anxious subscales as $0.81,0.78$, and 0.85 , respectively. Khodabakhshi-Koolaee et al. (2013) estimated the test-retest reliability of the scale within a one-month interval as equal to 0.95 . In this study, the reliability index of the scale was calculated as 0.89 using Cronbach's alpha coefficient.

Self-Report Measure of Spiritual Intelligence: This instrument was developed by King (2008). It contains 24 items, including critical existential thinking ( 7 items: $21,17,13,9,5,3, \& 1)$, personal meaning production ( 5 items: $23,19,15,11, \& 7)$, transcendent awareness (7 items: $22,20,18,14,10,2, \& 6)$, and conscious state ex- pansion (5 items: 24, 16, 12, 8, \& 4). The items were developed on a five-point Likert-type scale (1-5); the range of scores varies between 24-120 and its cutoff point is 96. In a pilot study, King administered the questionnaire to 619 undergraduate students (488 females \& 131 males) at the University of St. Petersburg. Accordingly, they reported a Cronbach's alpha coefficient of 0.95 and an average inter-item correlation of 0.36 for this scale. In another study to validate the scale, it was administered to 305 undergraduate students and the Cronbach's alpha coefficient was measured as 0.95 (King 2008; King \& DeCicco 2009). Hossein Jari and Zakeri (2010) estimated its reliability as equal to 0.93 using Cronbach's alpha coefficient. Besides, Cronbach's alpha coefficient values for the subscales of critical existential thinking, personal meaning production, transcendent awareness, and conscious state expansion were computed to be $0.78,0.68$, 0.74 , and 0.72 , respectively. In this study, the reliability index of the scale was calculated as 0.71 using Cronbach's alpha coefficient.

First, a list of marriage counseling and healthcare centers in municipal districts 5 and 6 of Tehran was prepared. However, given the restrictions imposed due to the Covid-19 outbreak and the inaccessibility of the respondents,

Table 1. The study participants' demographic characteristics

\begin{tabular}{ccc}
\hline Variable & Categories & No. (\%) \\
\hline Age group $(y)$ & $20-25$ & $86(21.5)$ \\
& $26-30$ & $138(34.5)$ \\
Educational level & $31-35$ & $176(44.0)$ \\
& Diploma & $155(38.75)$ \\
BA & MA & $148(37.0)$ \\
Number of children & PhD & $64(16.0)$ \\
& 1 & $33(8.25)$ \\
\hline Income level & 2 & $128(32.0)$ \\
& 3 & $141(35.2)$ \\
& 4 & $91(22.8)$ \\
& High & $38(9.5)$ \\
& Low & $2(0.5)$ \\
\hline
\end{tabular}


Table 2. The correlation matrix of the study participants' attachment styles and emotional divorce

\begin{tabular}{ccccc|}
\hline Attachment Style & $\mathbf{1}$ & $\mathbf{2}$ & $\mathbf{3}$ & $\mathbf{4}$ \\
\hline 1. Secure & 1 & & & \\
\hline 2. Avoidant & $0.296^{* *}$ & 1 & 1 & 1 \\
\hline 3. Anxious & $0.301^{* *}$ & 0.077 & $0.711^{* *}$ & Client- Centered Nursing Care \\
\hline 4. Emotional divorce & $-0.325^{*}$ & 0.032 & & \\
\hline${ }^{*} \mathrm{P}<0.05 ;{ }^{* *} \mathrm{P}<0.01$. & & &
\end{tabular}

most of the questionnaires were distributed online among the respondents and were completed from April 2020 to August 2020. The collected data were analyzed by descriptive statistics (mean, standard deviation, frequency, $\&$ percentage) and inferential statistics (correlation coefficient test and multiple regression analysis) using SPSS.

\section{Results}

The demographic characteristics of the study subjects are presented in Table 1. Table 2 lists the relationship between attachment styles and emotional divorce in the study participants. Accordingly, there was a positive significant relationship between the anxious attachment style and emotional divorce. However, there was a negative significant relationship between the secure attachment style and emotional divorce.

Table 3 illustrates the correlation between emotional divorce and spiritual intelligence. As per Table 3, spiritual intelligence and its components (critical existential thinking, personal meaning production, transcendent awareness, \& conscious state expansion) were negatively and significantly correlated with emotional divorce among the study participants.

Before testing the research hypotheses, the assumptions of univariate and multivariate regression analysis of the variables and the normal distribution of the data were checked. The Kolmogorov-Smirnov test data indicated that the normality assumption of the data was established $(\mathrm{P}>0.05)$.

Regression analysis was run to test the main research hypothesis as per Tables 4 and 5 . As per Table 4 , the coefficient of determination $\left(\mathrm{R}^{2}\right)$ was equal to 0.213 . In other words, the components of spiritual intelligence together explained $21.3 \%$ of the variances of emotional divorce among the explored women applying for a divorce. In addition, F-values calculated for regression analysis were found to be significant $(\mathrm{P}<0.05)$; thus, the regression equation was statistically significant.

As per Table 5, the regression coefficients (B) for personal meaning production, transcendent awareness, and conscious state expansion were equal to $0.364,-0.240$, and 0.469. Additionally, the regression constant was measured as 0.831 . Furthermore, t-values and P-values $(\mathrm{P}<0.05)$ for the research variables indicated that all coefficients were statistically significant.

The highest beta coefficient $(\beta=-0.525)$ belonged to conscious state expansion; therefore, conscious state expansion presents a greater share in explaining the women's emotional divorce. In other words, conscious state expansion is a stronger predictor of emotional di-

Table 3. The correlation matrix of the study participants' spiritual intelligence and emotional divorce

\begin{tabular}{|c|c|c|c|c|c|c|}
\hline Attachment Style & 1 & 2 & 3 & 5 & 5 & 6 \\
\hline 1. Critical existential thinking & 1 & & & & & \\
\hline 2. Personal meaning production & $0.822^{* *}$ & 1 & & & & \\
\hline 3. Transcendent awareness & $0.798^{* *}$ & $0.759^{* *}$ & 1 & & & \\
\hline 4. Conscious state expansion & $0.670^{* *}$ & $0.699^{* *}$ & $0.840^{* *}$ & 1 & & \\
\hline 5. Spiritual intelligence & $0.919^{* *}$ & $0.899^{* *}$ & $0.937^{* *}$ & $0.837^{* *}$ & 1 & \\
\hline 6. Emotional divorce & $-0.237^{* *}$ & $-0.344^{* *}$ & $-0.296^{* *}$ & $-0.421^{* *}$ & $-0.348^{* *}$ & 1 \\
\hline
\end{tabular}


Table 4. The results of synchronous regression model for predicting emotional divorce

\begin{tabular}{ccccc}
\hline Model & Correlation $(\mathbf{r})$ & Coefficient of Determination $\left(\mathbf{R}^{2}\right)$ & $\mathbf{F}$ & Sig. \\
\hline 1 & 0.461 & 0.213 & 26.709 & 0.001 \\
\hline A predictors: (constant), Spiritual intelligence & Dependent variable: Emotional intelligence & Durbin-Watson statistic: 1.256 \\
\hline
\end{tabular}

vorce among women applying for a divorce. Moreover, the results of regression analysis suggested that personal meaning production and transcendent awareness can explain $29.3 \%$ and $-0.232 \%$ of the variances of emotional divorce in the study subjects.

Table 6 lists the results of the regression analysis for emotional divorce. The coefficient of determination $\left(\mathrm{R}^{2}\right)$ was equal to 0.519 . In other words, the attachment styles together explained $51.9 \%$ of the variances of emotional divorce among the study samples. Besides, P-values calculated for regression analysis were significant $(\mathrm{P}<0.05)$, implying that the regression equation was statistically significant.

According to Table 6, the regression coefficients (B) for secure and anxious attachment styles were -0.245 and 0.733 and the regression constant was measured as 3.979. Besides, $t$-values and $P$-values were less than 0.05 $(\mathrm{P}<0.05)$ for the research variables, suggesting that all coefficients were statistically significant.

The highest beta coefficient $(\beta=0.671)$ was related to the anxious attachment style; therefore, the anxious attachment style provides a greater share in explaining the women's emotional divorce. In other words, the anxious attachment style is a stronger predictor of emotional divorce among women applying for a divorce. Moreover, the secure attachment style can explain $-0.129 \%$ of the variances of emotional divorce in the study participants.

\section{Discussion}

The present study data suggested that avoidant and anxious attachment styles, as well as low spiritual intelligence, were predictors of emotional divorce in women, as indicated in previous studies (Fakhri et al. 2018; McDonald et al. 2016). It was also identified that the secure attachment style and its components were negatively and significantly related to emotional divorce; thus, the higher secure attachment in women seeking a divorce, the higher their marital satisfaction and positive attitude towards life, and the lower the rate of emotional divorce in them. Couples with a secure attachment style experience the highest level of security in their interpersonal relationship due to the positive attitudes they have towards selves and others. Positive perceptions, as characteristics of individuals with secure attachment styles, predict supportive behaviors and marital satisfaction in couples (Khodabakhshi-Koolaee et al. 2013; Alfasi, Gramzow \& Carnelley 2010). The stable mental state and effective and efficient behaviors of these individuals concerning their spouse make them adopt a secure attachment style and establish more satisfactory social interactions. They also tend to express love and intimacy more frequently, trust in themselves and others, enjoy their relationships, are not worried about being rejected, and have a more

Table 5. The regression coefficients for the variables used to predict emotional divorce

\begin{tabular}{|c|c|c|c|c|c|c|}
\hline \multirow{2}{*}{ Model } & \multirow{2}{*}{ Variable } & \multicolumn{2}{|c|}{ Non-standardized Coefficients } & \multirow{2}{*}{$\begin{array}{c}\text { Standardized Coefficients } \\
\text { Beta }\end{array}$} & \multirow{2}{*}{$\mathbf{t}$} & \multirow{2}{*}{ Sig. } \\
\hline & & B & SD & & & \\
\hline \multirow{5}{*}{1} & Constant & 0.831 & 1.027 & & 0.809 & 0.419 \\
\hline & Critical existential thinking & -0.155 & 0.081 & 0.170 & -1.903 & 0.058 \\
\hline & Personal meaning production & 0.364 & 0.105 & 0.293 & 3.484 & 0.001 \\
\hline & Transcendent awareness & -0.240 & 0.105 & -0.232 & -2.278 & 0.023 \\
\hline & Conscious state expansion & 0.649 & 0.104 & 0.525 & 6.237 & 0.000 \\
\hline \multicolumn{7}{|c|}{ Dependent variable: Emotional divorce } \\
\hline
\end{tabular}


Table 6. The regression coefficients for the variables used to predict emotional divorce

\begin{tabular}{|c|c|c|c|c|c|c|}
\hline \multirow{2}{*}{ Model } & \multirow{2}{*}{ Variable } & \multicolumn{2}{|c|}{ Non-standardized Coefficients } & \multirow{2}{*}{$\begin{array}{c}\text { Standardized Coefficients } \\
\text { Beta }\end{array}$} & \multirow{2}{*}{$\mathbf{t}$} & \multirow{2}{*}{ Sig. } \\
\hline & & B & SD & & & \\
\hline \multirow{4}{*}{2} & Constant & 3.979 & 1.175 & & 3.385 & 0.001 \\
\hline & Secure attachment style & -0.245 & 0.074 & -0.129 & -3.323 & 0.001 \\
\hline & Avoidant attachment style & 0.046 & 0.091 & 0.019 & 0.503 & 0.616 \\
\hline & Anxious attachment style & 0.733 & 0.041 & 0.671 & 18.047 & 0.000 \\
\hline \multicolumn{7}{|c|}{ Dependent variable: Emotional divorce } \\
\hline
\end{tabular}

positive understanding of their lives than individuals with insecure attachment styles (Anisworth et al. 2015).

Individuals who foster an avoidant attachment style experience withdrawal and alienation, and reject the possibility that others may help them in times of stress and unhappiness. Thus, these individuals are extremely reluctant to establish close and intimate relationships and unconsciously avoid them as soon as they feel that the relationship is getting intimate. Women with insecureavoidant attachment style tend to experience more conflict, less satisfaction, less stability, and shorter periods in their romantic relationships; all of which reduce couples' relationships and marital satisfaction and increase emotional divorce (Borst 2015; Yarnoz-Yaben 2010). Murphy believed that individuals with insecure anxiety attachment styles are more prone to surrender. This is because of the fear of rejection when encountering conflict and the spouse's anger; however, they argue more when their spouse is calm (Murphy 2012).

The study results also revealed that spiritual intelligence was negatively and significantly correlated with emotional divorce. As spiritual intelligence increases, emotional divorce decreases. Besides, conscious state expansion was found as a stronger predictor of emotional divorce in women. The present study results were in line with another study. Carnesecca concluded that individuals with secure attachment styles present higher spiritual intelligence, compared to those with insecure attachment styles (Carnesecca Emmar 2020).

Accordingly, applying critical existential thinking, personal meaning production, and conscious state expansion can be effective in enhancing marital satisfaction and declining emotional divorce. This is because spiritual intelligence provides a framework for identifying and organizing valuable skills, competencies, and guidance, including a set of required beliefs and values. By resorting to spiritu- ality, women's adaptability increases and these characteristics can affect their married life. Individuals with strong religious attitudes in their behaviors act following the values and ethics; they also enjoy desirable interpersonal relationships. Besides, spiritual intelligence also focuses on interpersonal relationships (King et al. 2012).

The present study was conducted with limitations. First, due to the COVID-19 outbreak, there were some restrictions in selecting the individuals who met the inclusion criteria of the research. Therefore, the participants were selected using the non-random convenience sampling method. Second, a questionnaire is a self-reporting measurement and respondents might answer them carelessly or with doubt; thus, this may further undermine the generalizability of the obtained results.

\section{Conclusion}

The present study data indicated that avoidant and anxious attachment styles and spiritual intelligence can predict emotional divorce among women. Paying attention to ps y chological and personality characteristics, such as spiritual intelligence and attachment styles can affect spouse selection, marriage, and marital stability. Therefore, raising premarital awareness and knowledge, holding training courses, and providing premarital guidance and counseling services can lead to higher knowledge and satisfaction in couples.

\section{Ethical Considerations}

\section{Compliance with ethical guidelines}

This study was approved by the Ethics Committee of Islamic Azad University, Tehran North Branch (Code: IR.IAU.TNB.REC.1399.036). All ethical principles are considered in this article. The participants were informed about the purpose of the research and its implementation 
stages. They were also assured about the confidentiality of their information and were free to leave the study whenever they wished, and if desired, the research results would be available to them.

\section{Funding}

This study was extracted from the $\mathrm{PhD}$. dissertation of first author at the Department of Counseling \& Guidance, Faculty of Human Science, Rudehen Branch, Islamic Azad University, Rudehen.

\section{Authors' contributions}

All authors equally contributed to preparing this article.

\section{Conflict of interest}

The authors declared no conflict of interest.

\section{Acknowledgments}

The authors would like to thank the staff and managers of the Municipality of Tehran.

\section{References}

Ainsworth, M. D. S., et al., 2015. Patterns of attachment: A psychological study of the strange situation, Routledge, New York. [DOI:10.4324/9781315802428]

Alfasi, Y., Gramzow, R. H., \& Carnelley, K. B., 2010. Adult attachment patterns and stability in esteem for romantic partners. Personality and Individual Differences, 48(5), pp. 607-11. [DOI:10.1016/j.paid.2009.12.016]

Amirian, M. E., \& Fazilat-Pour, M., 2016. Simple and multivariate relationships between spiritual intelligence with general health and happiness. Journal of Religion and Health, 55(4), pp. 1275-88. [DOI:10.1007/s10943-015-0004-y] [PMID]

Borst, J. B., 2015. A systematic review of the effects of family conflict: Focusing on divorce, infidelity, and attachment style [Internet]. Cited 25 April 2021, https://sophia.stkate.edu/ msw_papers/426/

Bhullar, A., 2015. The growth of spiritual intelligence. Indian Journal of Educational Studies: An Interdisciplinary Journal, 2(1) pp. 122-31. https://ccemohali.org/img/Ch\%2018\%20Dr\%20 Amrita\%20Bhullar.pdf

Carnesecca Emma R., 2020. The relationship between spiritual intelligence, connectedness, and attachment [Internet]. Cited 25 April 2021, https://encompass.eku.edu/swps/2020/undergraduate/40

Collins, N. L., \& Read, S. J., 1990. Adult attachment, working models, and relationship quality in dating couples.
Journal of Personality and Social Psychology, 58(4), pp. 644-63 [DOI:10.1037/0022-3514.58.4.644] [PMID]

Fakhri, M., Mahdavianfard, R., \& Kimiaee, S. A. K., 2018. [Prediction of the probability of divorce based on avoidant attachment, anxiety attachment and family problem solving skills (Persian)]. Counseling Culture and Psychotherapy, 9(33), pp. 207-22. [DOI:10.22054/QCCPC.2018.28605.1716]

Fraley, R. C., \& Heffernan, M. E., 2013. Attachment and parental divorce: A test of the diffusion and sensitive period hypotheses. Personality and Social Psychology Bulletin, 39(9), pp. 1199213. [DOI:10.1177/0146167213491503] [PMID]

Gottman, J. M., \& Gottman, J. S., 2008. Gottman method couple therapy. Clinical Handbook of Couple Therapy, 4(8), pp. 138-64. https:// psycnet.apa.org/record/2008-09621-005

Gottman, J. M., 2002. Marital research in the 21 st century. Family Process, 41(2), pp. 159-97. [DOI:10.1111/j.15455300.2002.41203.x]

Hashemi, L., \& Homayuni, H., 2017. Emotional divorce: Child's well-being. Journal of Divorce \& Remarriage, 58(8), pp. 631-44. [DOI:10.1080/10502556.2016.1160483]

Hossein Jari, M., \& Zakeri, H., 2010. [The effect of studying university majors, religious and art sciences on spiritual intelligence: A trial for validation and measuring reliability of spiritual intelligence scale (Persian)]. Quarterly of Educational Measurement, 1(1), pp. 1-21. https:/ /jem.atu.ac.ir/article_2644. $\mathrm{html}$ ?lang=en

Katz, L. F., \& Gottman, J. M., 1997. Buffering children from marital conflict and dissolution. Journal of Clinical Child Psychology 26(2), pp. 157-71. [DOI:10.1207/s15374424jccp2602_4] [PMID]

Khodabakhshi-Koolaee, A., Chaeichi Tehrani, N., \& Sanagoo, A., 2019A. [The relationship between spiritual intelligence and emotional intelligence with self-compassion of nursing students (Persian)]. Iranian Journal of Medical Education, 19, pp. 44-53. https://ijme.mui.ac.ir/article-1-4697-en.htm

Khodabakhshi-Koolaee, A., Falsafinejad, M. R. \& Sabourei, Z., 2019B. [The study of the prevalence of dimensions and components of emotional divorce in married nurses in Tehran hospitals (Persian)]. Iranian Journal of Rehabilitation Research in Nursing, 5(3), pp. 39-47. [DOI:10.21859/ijrn.05036]

King, D. B., \& DeCicco, T. L., 2009. A viable model and selfreport measure of spiritual intelligence. International Journal of Transpersonal Studies, 28(1), pp. 68-85. [DOI:10.24972/ ijts.2009.28.1.68]

King, D. B., 2008. Rethinking claims of spiritual intelligence: a definition, model and measure [MSc. thesis]. Peterborough, Trent University. https://www.scienceopen.com/ document?vid=d25347f9-077d-4ac2-a401-2c01dad40f73

King, D. B., Mara, C. A., \& DeCicco, T. L., 2012. Connecting the spiritual and emotional intelligences: Confirming an intelligence criterion and assessing the role of empathy. International Journal of Transpersonal Studies, 31(1), pp. 11-20. [DOI:10.24972/ ijts.2012.31.1.11]

Khodabakhshi-Koolaee, A., et al., 2013. Fear of intimacy and attachment styles in women who apply for divorce. Middle East Journal of Psychiatry \& Alzheimers, 4(1), pp. 36-9. [DOI:10.5742/ MEJPA.2013.41182] 
Liu, Y., \& Froese, P., 2020. Faith and agency: The relationships between sense of control, socioeconomic status, and beliefs about god. Journal for the Scientific Study of Religion, 59(2), pp. 311-26. [DOI:10.1111/jssr.12655]

MacDonald, K., Patch, E. A., \& Figueredo, A. J., 2016. Love, trust, and evolution: Nurturance/love and trust as two independent attachment systems underlying intimate relationships. Psychology, 7(2), 238-53. [DOI:10.4236/psych.2016.72026]

Murphy, V. M., 2012. Understanding attachment anxiety and paradoxical reactions to conflict with romantic partners: The moderating role of attachment related threat [MSc. thesis]. Kingston, Queen's University. https:/ / qspace.library.queensu.ca/handle/1974/7347

Olson D. H. L., \& DeFrain J, D., 2002. Marriages and families: Intimacy, diversity, and strengths. New York, McGraw-Hill. https://books.google.com/books?id=HcljVeOoOCkC\&q

Özmen, O., \& Atik, G., 2010. Attachment styles and marital adjustment of Turkish married individuals. Procedia-social and Behavioral Sciences, 5, pp. 367-71. [DOI:10.1016/j.sbspro.2010.07.106]

Özmen, O., \& Atik, G., 2010. Attachment styles and marital adjustment of Turkish married individuals. Procedia-social and Behavioral Sciences, 5, pp. 367-71. [DOI:10.1016/j.sbspro.2010.07.106]

Pakdaman, S. H., 2001. The study of attachment and society seeking in adolescents [PhD. dissertation]. Tehran, Tehran University.

Pines, A., 2013. Couple burnout: Causes and cures. New York, Routledge. [DOI:10.4324/9781315022291]

Roper, S. W., Fife, S. T., \& Seedall, R. B., 2020. The intergenerational effects of parental divorce on young adult relationships. Journal of Divorce $\mathcal{E}$ Remarriage, 61(4), pp. 249-66. [DOI:10.1080 /10502556.2019.1699372]

Solomon, B. C., \& Jackson, J. J., 2014. Why do personality traits predict divorce? Multiple pathways through satisfaction. Journal of Personality and Social Psychology, 106(6), pp. 978-96. [DOI:10.1037/a0036190] [PMID]

Yárnoz-Yaben, S., 2010. Attachment style and adjustment to divorce. The Spanish Journal of Psychology, 13(1), pp. 210-9. [DOI:10.1017/S1138741600003796] [PMID] 
This Page Intentionally Left Blank 